\section{Pattern of presentation of patella instability at the nation- al orthopaedic hospital, Dala Kano, Nigeria}

Celestine Nkanta, ${ }^{1}$ AI Alabi, ${ }^{1}$ Mustapha Ibrahim Usman, ${ }^{2}$ Soliudeen Arojuraye Adebayo, ${ }^{1}$ Ndubuisi Okoh ${ }^{1}$

${ }^{1}$ Arthroscopy and Sports Medicine unit, Clinical Services and Training Department, National Orthopedic Hospital, Dala Kano; ${ }^{2}$ Surgery Department, Bayero University Kano, Aminu Kano Teaching Hospital, Kano, Nigeria

\begin{abstract}
Patella instability is a clinical condition in which patella dislocation had occurred at least twice, or where patella instability following initial dislocation had persisted for more than three months. It can be unilateral or bilateral. Females are more affected, and it can affect the quality of life of the individual affected. This study is a retrospective survey of all patients who had recurrent patella dislocation at National Orthopedic hospital, Dala, Kano between January 2009 and November 2019. A total of 49 patients were treated with recurrent patella dislocation were found with a predominant young age (11-20 years-old) and a female preponderance $(56.4 \%)$. Pain, instability or both are the main forms of presentation. Trauma, ligamentous laxity as well as hypoplasia of femoral condyle were risk factors identified. Arthroscopic medial plication and lateral release and was done in $28(71.8 \%)$ patients as a means of treatment. Three patients (7.7\%) had medial patellofemoral ligament reconstruction (MPFLR) while the remaining 8 patients $(20.5 \%)$ were managed non-operatively.
\end{abstract}

\section{Introduction}

Definitions of patella instability abound. It can be defined as the condition where patella dislocation had occurred at least twice, or where patella instability following initial dislocation had persisted for more than three months. ${ }^{1}$ It is used to signify a clinical entity or diagnosis (e.g., a traumatic dislocation of the knee cap). It is used as a sign on physical examination, signifying the ability to translate the patella out of the groove in a passive fashion. It can be a symptom, typically a giving way of the knee as a result of the patella slipping out of the trochlear groove or quadriceps inhibition the result of pain. The semantics of the patellofemoral joint, its symptoms, injuries, and diseases, are particularly confusing. ${ }^{2}$

Patellofemoral instability is a challenging treatment problem for an orthopaedic surgeon. The patellofemoral joint has a low degree of congruency by nature hence it is susceptible to dislocation. ${ }^{1}$ Dislocation is a result of anatomical abnormalities and/or insufficient soft tissue restraint. Other risk factors that predispose to patella instability are female sex, patella alta, external tibial torsion, femoral torsional deformity, increased Q-angle, trochlea dysplasia, soft tissue dysplasia, ligament laxity to mention a few. ${ }^{2}$

This study was designed to evaluate the pattern of patella instability presenting at the National Orthopedic Hospital Dala, Kano, Nigeria.

\section{Materials and Methods}

Medical record search of all patients from January 2009 to November 2019 using the diagnosis of recurrent patella dislocation performed at the National Orthopaedic Hospital Dala, Kano, revealed a total of 49 patients. The data was extracted and retrospectively analyzed. Only patients with patella instability of any cause at any age were included. Patients' demographics, laterality, risk factors, frequency of dislocation, treatment offered as well complications were analyzed using SPSS version 23 for Windows. Hospital Research Ethics Committee approval was obtained for the study.

\section{Results}

During the study period, a total of 49 patients were treated for recurrent patella dislocation. The mean age of the patients was $17.2 \pm 6.7$ years. Majority of our patients $23(59 \%)$ were between the ages of 11 and 20 years. Female gender accounts for $56.4 \%$ of the patients. Table 1 below shows the age and sex distribution of the patients.

Table 1. Age and sex distribution.

\begin{tabular}{ccc} 
Biodata & Frequency & Percentage (\%) \\
Age range & & \\
$0-10$ & 4 & 10.3 \\
$11-20$ & 23 & 59.0 \\
$21-30$ & 10 & 25.6 \\
$31-40$ & 2 & 5.1 \\
Gender & & \\
Male & 17 & 43.6 \\
Female & 22 & 56.4 \\
\hline
\end{tabular}

Correspondence: Dr Mustapha Usman Ibrahim, Surgery Department, Bayero University Kano / Aminu Kano Teaching Hospital, Kano, Nigeria.

E-mail: mustyibro90@gmail.com

Key words: patella instability, presentation pattern.

Contributions: the authors contributed equally.

Conflict of interest: the authors declare no potential conflict of interest.

Ethics approval and consent to participate: Hospital Research Ethics Committee approval was obtained for the study.

Received for publication: 9 December 2019. Revision received: 6 February 2020.

Accepted for publication: 6 February 2020.

This work is licensed under a Creative License (CC BY-NC 4.0).

CC Copyright: the Author(s), 2019

Licensee PAGEPress, Italy

Pyramid Journal of Medicine 2020; 3:75 doi:10.4081/pjm.2020.75

Figure 1 below summarizes the mode of presentation. The commonest mode of presentation was instability as presented by $24(64.5 \%)$ patients. Three $(7.7 \%)$ patients presented with pain only

More than half $(56.4 \%)$ of the patients presented with generalized ligamentous laxity, $8(20.5 \%)$ patients had previous history of trauma while the remaining nine (23.1\%) patients had hypoplastic lateral femoral condyle as the cause of recurrent dislocation (Figure 2).

The commonest treatment in our center is arthroscopic medial plication and lateral release and this was done in $28(71.8 \%)$ patients. Three patients $(7.7 \%)$ had medial patellofemoral ligament reconstruction (MPFLR) while the remaining 8 patients $(20.5 \%)$ were managed nonoperatively, as shown in Figure 3. Commons Attribution NonCommercial 4.0 


\section{Discussion}

Recurrent patella dislocation is more common in females especially between ages of 10-17 years. ${ }^{2,3}$ Our study also revealed a female preponderance, with prevalence within the ages $11-20$ years. The risk factors for recurrent patellar instability are well described and include ligamentous laxity and anatomic maldevelopment. Other aetiological factors documented include maldevelopment of the patella, which may be too high or too small; valgus deformity of the knee; external tibial torsion or a primary muscle defect. ${ }^{4,5}$ In the present study, the most common aetiologic factor is

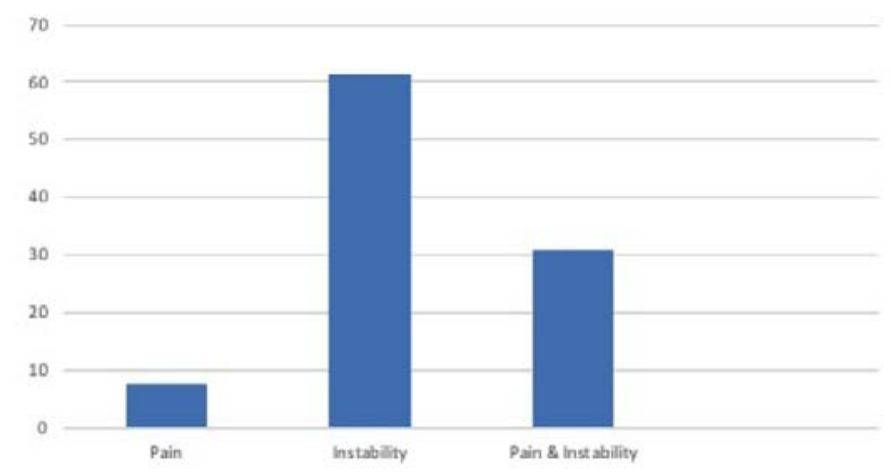

Figure 1. Modes of presentation.

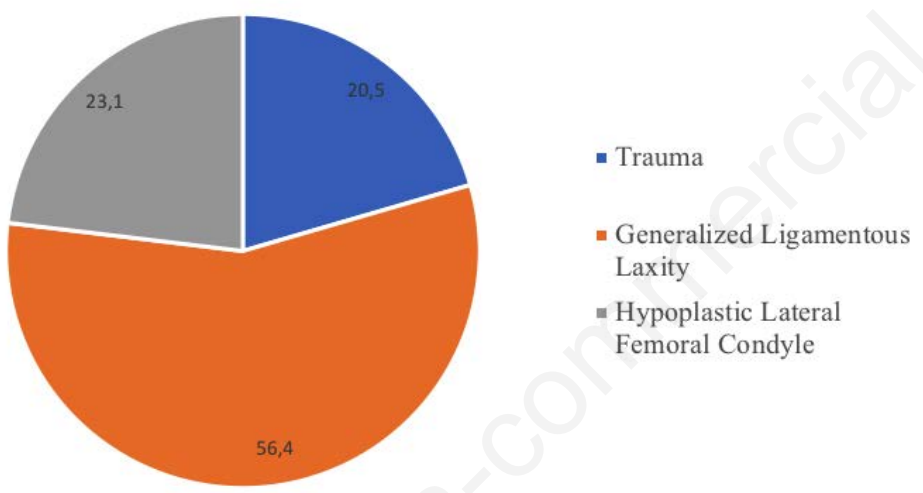

Figure 2. Aetiology.

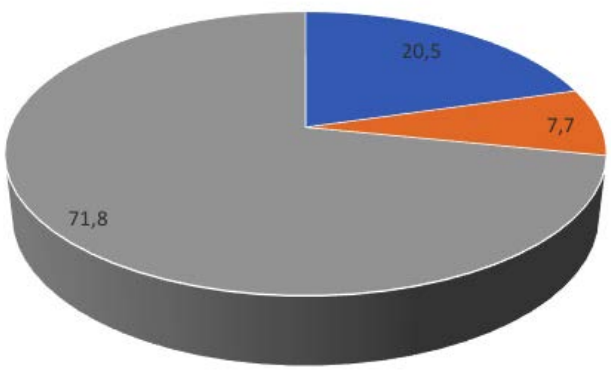

- Nonoperative

- Medial Patellofemoral Ligament Reconstruction

- Arthroscopic Medial Plication \& Lateral Release

Figure 3. Treatment methods.

generalized ligamentous laxity, which was present in $56.4 \%$ of the patients. The presentation of the patients varies; the most common presentation is that of instability and or pain. ${ }^{6,7}$ These were also demonstrated by our study.

\section{Conclusions}

Recurrent patella dislocation is seen commonly in adolescent. It affects more females than males. The risk factors are well known and can be managed nonoperatively and surgically.

\section{References}

1. Fithian DC, Paxton EW, Stone ML, et al. Epidemiology and natural history of acute patella dislocation. Am J Sports Med 2004;32:1114-21.

2. Arendt EA, Fithian DC, Cohen E. Current concept of lateral patella dislocation. Clin Sports Med 2002 ;21:449-519.

3. Aglietti P, Buzzi R, De Biase P, Giron F. Surgical treatment of recurrent dislocation of the patella. Clin Orthop 1994;308:8-17.

4. Scuderi G. Surgical treatment for patella instability. Orthop Clin N Am 1992;23:619-30.

5. Smith TO, Song F, Donell ST, et al. Operative versus non- operative management of patellar dislocation. A meta-analysis. Knee Surg Sports Traumatol Arthrosc 2011;19:988-98.

6. Dejour H, Walch G, Nove-Josserand L, et al. Factors of patellar instability: an anatomic radiographic study. Knee Surg Sports Traumatol Arthrosc 1994;2:1926.

7. Christiansen SE, Jakobsen BW, Lund B, et al. Isolated repair of the medial patellofemoral ligament in primary dislocation of the patella: a prospective randomized study. Arthroscopy 2008;24:881-7. 